\title{
Prevalence of human papilloma virus in anal duct in patients with H.I.V.
}

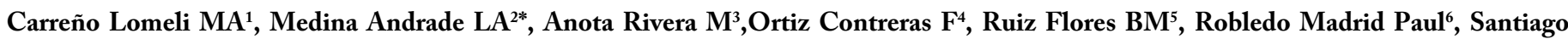 \\ Ramirez NI ${ }^{6}$, Fuentes Duran $\mathrm{S}^{6}$, Gallaga Rojas Marco $\mathrm{A}^{6}$ and Selene Noemi Montoya Valdez ${ }^{7}$ \\ ${ }^{1}$ Colon and rectum service, Militar Central Hospital, México \\ ${ }^{2}$ General Surgery Department, Regional General Hospital \#30, IMSS, México \\ ${ }^{3}$ Colon and rectum service, Regional General Hospital \#1, IMSS, México \\ ${ }^{4}$ Head of Training, Regional General Hospital \#1, IMSS, México \\ ${ }^{5}$ General Surgery Department, Regional General Hospital \#17, IMSS, México \\ ${ }^{6}$ Sanity Graduated Militar School, México \\ ${ }^{7}$ General Surgery Department, Colima Universitaryl Regional Hospital, Mexico
}

\begin{abstract}
Background: Anal duct tumors have a low prevalence. An association has been established between V.P.H. infection and progression to anal intraepithelial neoplasm (AIN), that is a pre-invasive stage of epidermoid carcinoma (EC). Male patients with H.I.V. keeping sexual activity with other males have a higher prevalence of V.P.H. and A.I.N. that H.I.V. negative ones. The objective of this study was determine the prevalence of papilloma virus in anal duct in male patients with H.I.V. in a second level of attention Hospital.

Material and methods: This was a descriptive case series study developed in a second level of attention hospital in México. Sample size was not probabilistic, with consecutive cases from March to July 2014. Seropositive patients having sexual relations with other males were included and an anal cytology studied searching H.P.V., A.I.N. and E.C. Statistical analysis was realized with frequencies, ranges, medians and percentages with Microsoft Excel 2007 ${ }^{\circledR}$.

Results: A total of 113 male patients with H.I.V. were included. Anal cytology reveals a prevalence of $4.42 \%$ for H.P.V., 4.42\% for low grade A.I.N., $87 \%$ without pathology and 3.5\% with inadequate sample. Average age was 43.7 years, the number of sexual partners with a median of 7 , lymphocytes T CD4+ average of 592 cell/ $\mathrm{mm} 3$, and undetectable viral charge in $80.53 \%$ of patients. The more frequent H.I.V. clinical stage was A1 with $60.17 \%$.

Conclusions: The prevalence of H.P.V. in anal conduct and low grade A.I.N. was lower than reported in national and international literature. We consider that a good immunologic control, with an undetectable viral charge and low H.I.V. clinical stage, combined with safer sexual practices are responsible of the low prevalence of H.P.V. and A.I.N., but nevertheless other studies are needed to confirm this hypothesis.
\end{abstract}

Clinical Registry: F-2014-3609-13.

\section{Introduction}

In 2013 the prevalence of people with H.I.V. diagnosis in méxico was 174,303 , with 9,017 new cases that year. From the new cases, 4,657 were diagnosed with AIDS and 4,360 with H.I.V. initially. In 2012 the mortality rate of patients with AIDS for each 100,000 people was 4.2. AIDS is more frequent presented between $30-34$ years with 32,752 cases (19.5\%) and between 25.29 years (17.9\%). Notified cases are more frequent in men with $82.1 \%[1,2]$.

Anal duct and anal margin tumors are rare. In USA the incidence is about 4,650 cases per year and 690 deaths in 2007. In the last 25 years that incidence has increased in both genders from 1.06 cases by 100000 people in 1979 to 2.06 cases by 100000 people in year 2000 . This increase in predominant on early stages of the disease, probably secondary to detection programs in high risk population. In advanced satges of the disease this increase has been constant. Anal duct and anal margin cancer have a prevalence of 1 to $4 \%$ of malignant tumors of inferior intestinal tract [3-6].

In the past those tumours were more frequent in woman in a proportion of 2:1 affecting preferably patients over 50 years old. In the last 30 years the incidence has increased up to $96 \%$ in males and $36 \%$ in females. This increase has been more frequent in men that have sex with men, with numbers near the ones for cervical cancer before cervical cytology was stablished as screening method [3-6].

The more important identified risk factor is the Human Papiloma Virus (H.P.V.) infection, where virus transmission by anoreceptive contacts, principally in men having sex with men, is the more significative association for anal cancer [4,5].

Ranges are even more alarming in patients with Human Imminodeficiency Virus (H.I.V.). Other risk factors include high

Correspondence to: Medina Andrade LA, General Surgery Department, Regional General Hospital \#30, IMSS, México, Tel: (+52) 9981114201; E-mail: buismedina_5@hotmail.com

Received: September 10, 2016; Accepted: October 14, 2016; Published: October 19,2016 
number of sexual partners, smokers, genital and anal warts, and anoreceptive sexual intercourse. A direct relation has been stablished between H.P.V. infection and progression to Anal Intraepithelial Neoplasia (A.I.N.), which in turn may progress to Anal Epidermoid Carcinoma (A. E.C.) [7-11].

Recently research about A.I.N., that share many characteristics with Intraepithelial cervical neoplasia (I.C.N), as a pre-inveasive stage of A. E.C., as I.N.C. with cervical cancer. There exist a few registries in the world about the A.I.N., and less in México [7,10].

The prevalence of H.P.V. in the anal duct in seropositive patients in México is unknown exactly, and if the risk factors include demographic and sexual intercourse habits, including age of H.I.V. diagnosis, number of sexual partners and use of barrier methods, the H.P.V. prevalence on anal duct could be different in our population, and maybe diminished in a population conforming a H.I.V. follow up program (CLISIDA), with sexual education and periodic consultation.

The mentioned is a public health problem that is increasing over men who have sex with men and are H.I.V. seropositive, and the rutinary study to found H.P.V., A.I.N. and the timely treatment of this lessions is not part of current guidelines. The objective of this study is to determine the prevalence of H.P.V. in anal duct of male patients with H.I.V. in a population conforming a H.I.V. follow up program (CLISIDA), with sexual education and periodic consultation.

\section{Material and methods}

This study was a case series descriptive study, prospective and unicentric. This work was developed from March to July 2014 in the General Regional Hospital No. 1. "Carlos MacGregor Sánchez Navarro", a second level of attention hospital in México City. The study was registered and authorized by the ethics commite with clinical registry number F-2014-3609-13.

\section{Sample size}

A non-probabilistic sample, with consecutive cases by convenience from March to July 2014 was used. Patients with inclusion criteria were send by CLISIDA program (a program specialized in H.I.V. patient attention, follow up and education), to colon and rectum service. Inclusion criteria were homosexual men with H.I.V., over 18 years and accepting to be part of the study. Patients with previously malignant anal lessions or H.P.V. vaccination were excluded.

\section{Interventions}

From March to July 2014 patients included in the CLISIDA program, a program to follow up patients with H.I.V. infection, were refered to the colon and rectum consultation for an evaluation. Patients fulfilling the inclusion criteria and after explaining the objectives of the study, benefits and risks, were asked to sign an informed consent.

A questionnaire about general characteristics and risk factors related with the studied disease were collected. After finishing the questionnaire, a perianal exploration was developed searching perianal lessions like anal fissure, fistula, abscess or condylomas. After this a citobrush was introduced 2 to $3 \mathrm{~cm}$ in the anal duct, a $360^{\circ}$ turn were realized 30 times, the citobrush removed, spread on a slide and fixed.

To finish a rectal digital exam was performed to search for tumours and an anoscopy to see the four quadrants searching for lessions suggesting malignancy. In case of positive lessions patients were refered for surgical exploration and biopsy. Samples were analized in pathology service by Papanicolau tinction and diagnosed by Bethesda classification in: insufficient sample, cytopathologic effect of H.P.V., low grade intraepithelial anal neoplasia and high grade intraepithelial anal neoplasia. For sample consideration as suitable it must contain squamous and glandular epithelium. In case of cytophatic results with presence of H.P.V. or A.I.N. they were treated with Imiquimod in anal conduct as recommended by international guidelines and another exam in 6 months to evaluate abscense or progression of the disease.

\section{Data analysis}

Data was collected in an Excel 2007 data base and analised with descriptive statistics including medium, average, percentages and frequencies. Comparative test was not performed by the study design.

\section{Results}

A total of 113 patients fulfill the inclusion criteria and were included in the mentioned time period. The total of this were men, with average age of 43 years (24-74 years). H.I.V. diagnosis were reviewed with file registry and for this data the average time of disease evolution was 9.7 years (a month to 30 years) (Table 1).

At physical exam and anoscopy 16 patients (14.15\%) were detected with perianal condylomas, 7 (6.19\%) with hemorroidal disease, 1 with anal fissure, $3(2.65 \%)$ with scarred anal fissure and 1 with atypical fissure (laeral).

From this 13 patients $(11.5 \%)$ have receive previous treatment with condylomas electrofulguration or resection, 4 (3.53\%) with Ferguson hemorroidectomy, 2 (1.76\%) with fistulotomy and $1(0.88 \%)$ fisurectomy.

About sexual behavior and sexual habits, the average of sexual partners was 50.1 ( 1 to 1,200$)$. The use of condom was reered in all sexual intercourse with men in $76 \%$ of times, $24 \%$ refer to use it in some ocations and none refer not to use it (Table 1).

The initial state of H.I.V. was B3 in $24.77 \%$, followed by C3 in $17.7 \%$ and $\mathrm{C} 1$ with none (Table 2, Figure 1). Actual state of the disease was $\mathrm{A} 1$ in $60.17 \%, \mathrm{~A} 2$ in $34.51 \%$ and $\mathrm{A} 3$ in $5.3 \%$. (Table 3, Figure 2). Actual state of the disease presents an evident decrease after treatment and follow up in the program (Table 4, Figure 3). With respect to CD4+ lymphocyte count, average at H.I.V. diagnosis was 204.65 with a minimum count of 8 and maximum of 802 . Actual average count is 592.23 , with a minimum of 60 and maximum of 1524 (Table 1). Actual RNA H.I.V-1 Viral Charge average is 930.52 copies $/ \mathrm{ml}$, with $80.53 \%$ of patients with undetectable viral charge, with a range from 0 to 47,600 copies/ml. The use of antiretroviral therapy was documented in 111 patients $(98 \%)$. Anal cytology was normal in 99 patients $(87.61 \%)$, with

Table 1. Demographic data, sexual behaviour and H.I.V.

\begin{tabular}{|l|c|c|c|c|c|}
\hline & Average & Median & Maximum & Minimum & Mode \\
\hline Age (years) & 43.78 & 44 & 74 & 24 & 46 \\
\hline No. Sexual partners & 50.1 & 7 & 1200 & 0 & 10 \\
\hline Use of condom & & & & & \\
\hline Always & 76 & & & & \\
\hline Sometimes & 24 & & & & \\
\hline Never & 0 & & & & \\
\hline H.I.V. diagnosis to actual (years) & 9.79 & 9 & 30 & 0.8 & 5 \\
\hline Antiretroviral therapy use & 98.23 & & & & \\
\hline CD4 initially & 204.65 & 203 & 802 & 8 & 240 \\
\hline CD4 actually & 592.23 & 561 & 1524 & 60 & 463 \\
\hline Actual viral charge & 930.52 & 0 & 47600 & 0 & 0 \\
\hline
\end{tabular}


Table 2. Initial H.I.V. stage.

\begin{tabular}{|c|c|c|}
\hline Stage & Percentage & $\mathbf{N}=\mathbf{1 1 3}$ \\
\hline A1 & 3.53 & 4 \\
\hline A2 & 16.81 & 19 \\
\hline A3 & 3.53 & 4 \\
\hline B1 & 0.9 & 1 \\
\hline B2 & 27.4 & 31 \\
\hline B3 & 24.77 & 28 \\
\hline C1 & 0 & 0 \\
\hline C3 & 5.3 & 6 \\
\hline & 17.7 & 20 \\
\hline
\end{tabular}

Initial H.I.V. Stage

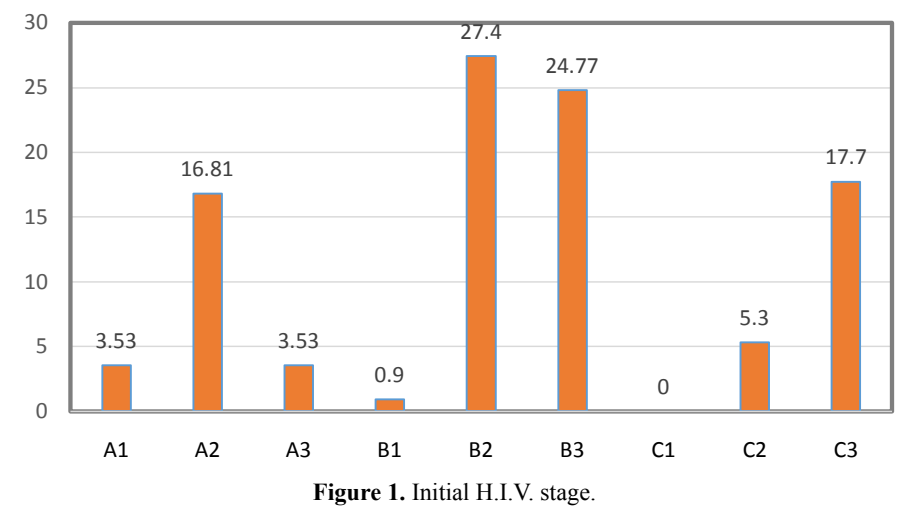

Table 3. H.I.V. stage at the present time of study.

\begin{tabular}{|c|c|c|}
\hline Stage & Percentage & $\mathbf{N}=\mathbf{1 1 3}$ \\
\hline A1 & 60.17 & 68 \\
\hline A2 & 34.51 & 39 \\
\hline A3 & 5.3 & 6 \\
\hline B1 & 0 & 0 \\
\hline B2 & 0 & 0 \\
\hline B3 & 0 & 0 \\
\hline C1 & 0 & 0 \\
\hline C2 & 0 & 0 \\
\hline C3 & 0 & 0 \\
\hline
\end{tabular}

Actual H.I.V. stage

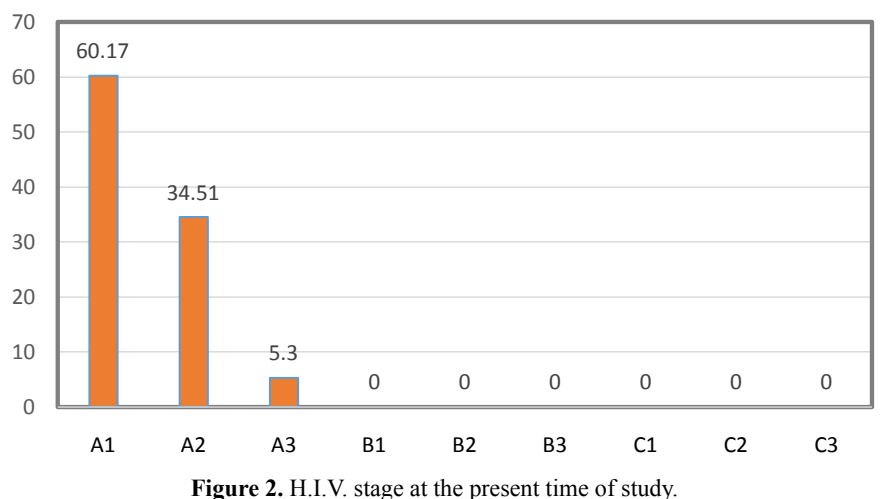

cytophatic effect by H.P.V. in $4.42 \%$, with low grade intraepithelial neoplasia in $4.42 \%$ and in 4 cases insufficient sample (Table 5). Finally, of the 99 patients in which anal cytology was normal, $10.61 \%$ had perianal condylomas, $13.27 \%$ with visible ones at physical exam; from the 5 with H.P.V. confirmed, one had a previous condyloma resection and two presented visible lesions at physical exam. In patients
Table 4. Comparison between initial and actual stages (\%).

\begin{tabular}{|c|c|c|}
\hline & Initial & Actual \\
\hline A1 & 3.53 & 60.17 \\
\hline A2 & 16.81 & 34.51 \\
\hline B1 & 3.53 & 5.3 \\
\hline B2 & 0.9 & 0 \\
\hline B3 & 27.4 & 0 \\
\hline C1 & 24.77 & 0 \\
\hline C2 & 0 & 0 \\
\hline & 5.3 & 0 \\
\hline
\end{tabular}

Stages comparison

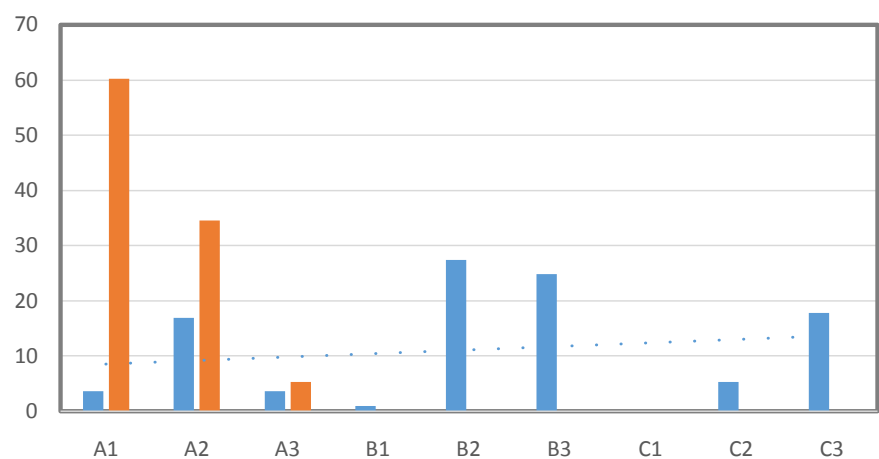

Figure 3. Comparison between initial and actual stages (\%). Blue: initial Orange: Actual

Table 5. H.P.V. prevalence.
\begin{tabular}{|l|c|}
\hline Characteristics & PREVALENCE \\
\hline Normal Cytology & 87.61 \\
\hline H.P.V. Prevalence & 4.42 \\
\hline Low Grade Intraepithelial Neoplasia & 4.42 \\
\hline Inadequate Sample & 3.53 \\
\hline
\end{tabular}

Table 6. Cythology/Condiloma relationship.

\begin{tabular}{|l|c|c|}
\hline & N= 113 & PERCENTAJE \% \\
\hline HPV +/Previous Condyloma & 1 & 0.88 \\
\hline HPV +/Actual Condyloma & 2 & 1.76 \\
\hline Low Grade Ain /Previous Condyloma & 1 & 0.88 \\
\hline Low Grade Ain /Visible Condyloma & 0 & 0 \\
\hline Normal/Previous Condyloma & 12 & 10.61 \\
\hline Normal/ Visible Condyloma & 15 & 13.27 \\
\hline
\end{tabular}

with low grade A.I.N. (5 patients), one refered previous condylomas electrofulguration (Table 6).

\section{Discussion}

Our study was developed in a second level of attention hospital "Dr. Carlos MacGregor Sánchez Navarro" from the Mexican Institute of Social Security, a hospital that have the service of a program called CLISIDA, which offer attention to 1,800 patients with H.I.V. and A.I.D.S., considering it as a national reference center. It is important to mention that there is no clinical guidelines or protocols about the screening of H.P.V. or precancerous lessions in seropositive patients. As refered in the international guidelins published by England, they recommend the realization of clinical guidelines and protocols according to each hospital needs specially in reference centers [12].

For this reason, the present study was realized, to analize and describe the behavior of this diseases in our population. Although it 
was a serie of cases study and don't try to found a risk factor relation between studied factors, we found a prevalence of $4.42 \%$ on H.P.V. in 113 seropositive men patients having sex with men, a lower prevalence that previously reported in other international series like the one by Dong-Yan Zhang in China [13], reporting a prevalence of $36.4 \%$ for H.P.V. in anal duct, the one by Sendagorta in Spain with $80.9 \%$, and the one by Palefsky in USA with 90\% [10,11].

Lymphocites T CD4+ were analized, with an initial average count of 204 cells $/ \mathrm{mm} 3$, ranging from 8 to 802 cells $/ \mathrm{mm} 3$, and actually with average count of 592 cells/mm3, ranging from 60 to 1,524 cells/ $\mathrm{mm} 3$. From the 113 patients, 111 were under antiretroviral therapy continuously, using condom $76 \%$ of cases and average of 7 sexual partners, reflecting good sexual habits comparing with other reports, and for this reason we consider it as factors that contribute to the low prevalence of H.P.V. and A.I.N. in the studied population, without clinical or immunologic deterioration [11, 14-17].

In 2012 a review and systematic analysis was published in Lancet about Global burden of cancers attributable to infections in 2008, considereing many infectous agents as carcinogenics, and based in GLOBOCAN 2008 statistics, it was reported that from the 12.7 millions of new cancer cases that year, $16.1 \%$ could be attributable to infectous agents, meaning around 2 millions of new cancer cases [18].

This fraction is higher in low developed countries (22.9\%) than in developed ones (7.4\%). Taking this in account and that the H.P.V. is included in this infectous agents, it is estimated that over $88 \%$ of the anal carcinoma cases are releated with this virus [18].

A study developed in China by Dong-Yan Zhan search for the prevalence of H.P.V. in a 408 men having sex with men population, founding $71.4 \%$ in patients with H.I.V. and $33.8 \%$ in seronegative ones. This results are comparable with the ones obtained in Rotterdam, Holanda, where the prevalence of anal H.P.V. in patients with H.I.V. was $76.9 \%$ and $36.4 \%$ respectively [14].

In a multivariate analysis about risk factors realted with H.P.V. infection was found that having more than 10 sexual partners in last 6 months favours infection. The frequent genotypes were H.P.V. 06 (8,2\%), $11(6.4 \%), 18(4.7 \%), 58(4.7 \%)$ and $52(4.2 \%)$. It is important to notice that actual H.P.V. vaccine cover genotypes $6,11,16$ and 18 but not 52 and 58 genotypes. This study mentions too that $86 \%$ of anal cancers are related with H.P.V. infection, with the men havin sex with men and H.I.V. infection having 1.5 more prevalence of H.P.V., and relative risk of anal cancer development of 5, comparing with men without the mentioned risk factors [14].

In October 2013 the work "Prevalence of Anal Intraepithelial Neoplasia among HIV-positive Mexican Men who Hav Sex with Men." by National Medical Center La Raza, presented in the IADS Europe congress, reported that of the 93 patients included $27 \%$ had normal cytology, $23 \%$ reactive inflammatory changes, $29 \%$ low grade intraepithelial neoplasia, 7\% I.A.N. of high grade, $3 \%$ herpes associated lessions and $9 \%$ inadequate sample. They concluded that with the $36 \%$ prevalence of I.A.N., it is necessary to perform another citology and confirmatory biopsy in patients with H.I.V., men having sex with men, and timely detect precancerous lessions, allowing timely diagnose and treatment.

British H.I.V. malignant associated diseases, published in 2014, recommended that all patients with H.I.V. and malignant diseases would be referred to experienced reference centers for this pathology management. In the case of anal cancer this guides recommend that health centers treating patients with H.I.V. would develop clinical guidelines for suspected anal cancer and precancerous lessions, although the screening with anal cytology is not recommended yet [12].

Anal cancer incidence in patients with H.I.V. is 40 times higher comparing with general population and this is presented at an earlier age. The incidence of anal cancer has increased the last years with the extensive use of anti retroviral therapy, this maybe secondary to the longer live of patients, allowing H.P.V. infection progression to dysplasia and anal cancer [5,10,12,19-21].

Anal cancer pathogenesis is very similar to cervical cancer, with papilloma virus infection progression to intraepithelial anal dysplasia and finally invasive anal cancer. This pathogenesis models suggest the use of anal cytology and high resolution anscopy as screening, followed by a local ablative therapy for I.A.N [16,22-30]. The use of this management is not recommended in international guidelines but it is suggested by some medical centers to install a screening program, and some cost-effective protocols have been developed with positive and negative results $[12,15,28,30]$.

Anal cancer clinical signs include rectal bleeding, pain and incontinence if sphincter are affected. Many patients could present asymptomatic, and the age of presentation is earlier in patients with H.I.V. For the inespecific symptomathology the diagnosis could be confused with hemorroidal disease or simple warts, for this reason we recommend to perform a rectal examn under anaesthesia in all suspicious cases [12]. Sendagorta, Fox and Olvera recommend to perform an anal cytology in all patients with risk factors for H.P.V. infection, with a high resolution anoscopy with biopsy in suspicious lesions as it has been recommended in other studies [10,28,29].

One weak point in our work is that was a cases series, and it needs a bigger sample size to dilucidate if the screening would be realized in an annual or biannual manner, including anal cytology in all male having sex with men patients and H.I.V. infection.

Other important point is the difference in stage presentation between our patients and the ones presented by the mentioned study in Nationa Medical Center La Raza, with a prevalence of H.I.V. stage C3 in $65.2 \%$, and $60.17 \%$ of A1 stage in our center. We consider that this is secondary to the good pharmacologic control and education of patients in our group center CLISIDA, both diminishing infection rates.

Actual viral charge is 930.52 copies/ml average in our population, and in $80.53 \%$ of patients it is undetectable, with a range from 0 to 47,600 copies $/ \mathrm{ml}$, reflecting viral suppression and adequate antiretroviral therapy as mentioned by 2008 Europe guidelines [1,5]. None international study analize the H.I.V. clinical stage as a risk factor to H.P.V. infection, and for this reason we suggest this analisis in future protocols.

\section{Conclusions}

In the present study with the use of anal cytology in the studied population, the prevalence of H.P.V. and low grade A.I.N. were lower than previously reported in the national and international literature. We consider that good inmmunologic control in the patients included, reflexed in an undetectable viral charge, low H.I.V. clinical stage and responsable sexual habits are the factors influencing this low prevalence of H.P.V. and A.I.N., but nevertheless we require a bigger sample size and other studies to confirm this theory. 


\section{References}

1. Castro KG, Ward JW, Slutsker L, Buehler J, Jaffe HW, et al. (1993) Revised classification system for HIV infection and expanded surveillance case definition for AIDS among adolescents and adults. JAMA 269: 729-730. [Crossref]

2. Brenchley JM, Price DA, Schacker TW, Asher TE, Silvestri G, et al. (2006) Microbial translocation is a cause of systemic immune activation in chronic HIV infection. Nat Med 12: 1365-1371. [Crossref]

3. Eggena MP, Barugahare B, Okello M, Mutyala S, Jones N, et al. (2005) T cell activation in HIV-seropositive Ugandans: differential associations with viral load, CD4+ T cell depletion, and coinfection. J Infect Dis 191: 694-701. [Crossref]

4. Sousa AE, Carneiro J, Meier-Schellersheim M, Grossman Z, Victorino RM (2002) CD4 $\mathrm{T}$ cell depletion is linked directly to immune activation in the pathogenesis of HIV-1 and HIV-2 but only indirectly to the viral load. J Immunol 169: 3400-3406. [Crossref]

5. Mónica Alonso, Omar Sued (2014) Antiretroviral treatment of infection V.I.H. in adults and adolescents. Recommendations for a public health approach.

6. Clumeck N, Pozniak A, Raffi F; EACS Executive Committee (2008) European AIDS Clinical Society (EACS) guidelines for the clinical management and treatment of HIVinfected adults. HIV Med 9: 65-71. [Crossref]

7. National Center for Prevention and Control of HIV / AIDS (2013) Epidemiological Monitoring of HIV / AIDS in Mexico National Registry of AIDS cases

8. Charúa Guindic L, Esquivel Ocampo EA, Villanueva Herrero JA, Jiménez Bobadilla B, Muñoz Cortés SB, et al. (2009) Anal intraepithelial neoplasia and infection by human papilloma virus in patients anorreceptivos. Gastroenterol Mex 74: 195-201

9. Friedlander MA, Stier E, Lin O (2004) Anorectal cytology as a screening tool for anal squamous lesions: cytologic, anoscopic, and histologic correlation. Cancer 102: 19-26. [Crossref]

10. Machalek D, Poynten M, Jin F, Fairley CK, Farmsworth A, et al. (2012) Anal human papillomavirus infection and associated neoplastic lesions in men who have sex with men: a systematic review and meta-analysis. Lancet Oncol 13: 487-500.

11. Sendagorta E, Herranz P, Guadalajara H, Zamora FX (2011) Early detection of anal intraepithelial neoplasia in high-risk patients. Actas Dermosifiliogr 102: 757-765. [Crossref]

12. Palefsky JM (2000) Anal squamous intraepithelial lesions in human immunodeficiency virus-positive men and women. Semin Oncol 27: 471-479.

13. Scholefield JH, Hickson WG, Smith JH, Rogers K, Sharp F (1992) Anal intraepithelial neoplasia: part of a multifocal disease process. Lancet 340: 1271-1273. [Crossref]

14. Pera M, Sugranes G, Ordi J, Trias M (1999) Association between infection with the human papillomavirus, premalignant lesions of anal cancer and HIV: a prospective study in patients with genital warts. Med Clin 113: 13-14.

15. Palefsky JM, Holly EA, Hogeboom CJ, Ralston ML, DaCosta MM, et al. (1998) Virologic, immunologic, and clinical parameters in the incidence and progression of anal squamous intraepithelial lesions in HIV-positive and HIV- negative homosexual men. J Acquir Immune Defic Syndr Hum Retrovirol 17: 314-319.
16. Chin-Hong PV, Palefsky JM (2002) Natural history and clinical management of anal human papillomavirus disease in men and women infected with human immunodeficiency virus. Clin Infect Dis 35: 1127-1134.

17. Salit IE, Lytwyn A, Raboud J, Sano M, Chong S, et al. (2010) The role of cytology (Pap tests) and human papillomavirus testing in anal cancer screening. AIDS 24: 1307-1313. [Crossref]

18. HIV Clinical guidelines of the New York State Department of Health (2007) HIV Clinical resources.

19. Kaplan JE, Benson C, Holmes KH, Brooks JT, Pau A, et al. (2009) Guidelines for prevention and treatment of opportunistic infections in HIV-infected adults and adolescents: recommendations from CDC, the National Institutes of Health, and the HIV Medicine Association of the Infectious Diseases Society of America. MMWR Recomm Rep 58: 1-207.

20. Kreuter A, Brockmeyer NH, Hochdorfer B, Weissenborn SJ, Stücker M, et al. (2005) Clinical spectrum and virologic characteristics of anal intraepithelial neoplasia in HIV infection. J Am Acad Dermatol 52: 603-608. [Crossref]

21. De Sanjosé S, Palefsky J (2002) Cervical and anal HPV infections in HIV positive women and men. Virus Res 89: 201-211. [Crossref]

22. Czosky-Murray C, Kamon J, Jones R, Smith K, Kinghorn G (2010) Cost- effectiveness of screening highrisk HIV-positive men who have sex with men (MSM) and HIVpositive women for anal cancer. Health Technology Assessment 14: 1-131.

23. Olvera Magaña P, Ramírez Mendoza P, Torres Peralta J, Torres Ibarra R, Ceniceros R (2009) Lesiones escamosas en sujetos que practican coito anal: comparación de hallazgos citológicos vs. Histológicos. Patología 49: 132-137.

24. Fox PA (2006) Human papillomavirus and anal intraepithelial neoplasia. Curr Opin Infect Dis 19: 62-66. [Crossref]

25. Scholefield JH, Johnson J, Hitchcock A, Kocjan G, Smith JH, et al. (1998) Guideline for anal cytology--to make cytological diagnosis and follow up much more reliable. Cytopathology 9: 15-22. [Crossref]

26. Chin-Hong PV, Palefsky JM (2002) Natural history and clinical management of anal human papillomavirus disease in men and women infected with human immunodeficiency virus. Clin Infect Dis 35: 1127-34.

27. Fox P (2009) Anal cancer screening in men who have sex with men. Curr Opin HIV AIDS 4: 64-67. [Crossref]

28. De Martel C, Ferlay J, Franceschi S, Vignat J, Bray F, et al. (2012) Global burden of cancers attributable to infections in 2008: a review and synthetic analysis. Lancet Oncol 13: 607-615. [Crossref]

29. Zhang DY, Yin YP, Feng TJ, Hong FC, Jiang N, et al. (2014) HPV infections among MSM in Shenzhen, China. PLoS One 9: e96364. [Crossref].

30. Bower M, Palfreeman A, Alfa-Wali M, Bunker C, Burns F, et al. (2014) British HIY Association guidelines for HIV-associated malignancies 2014. HIV Med 15 Suppl 2: 1-92. [Crossref]

Copyright: (C2016 Carreño Lomeli MA. This is an open-access article distributed under the terms of the Creative Commons Attribution License, which permits unrestricted use, distribution, and reproduction in any medium, provided the original author and source are credited. 